\title{
Comparative study of serum ferritin levels after oral supplementation with ferrous sulphate and carbonyl iron in mild iron deficiency anemia in pregnancy
}

\author{
N. CHANDRIKA * and K. C. VASUDHA \\ Department of Biochemistry, M. S. Ramaiah Medical College, MSR Nagar, Gokula, Bangalore, India. \\ *Corresponding author, E-mail: dr.chandrikar@gmail.com, Tel: Phone no.+919980518032
}

\begin{abstract}
Iron supplementation is almost universally recommended during pregnancy to correct or prevent iron deficiency. Iron status can be assessed prepartum by estimating blood hemoglobin concentration, serum iron, serum total iron binding capacity (TIBC) and serum ferritin. This study attempts to know the therapeutic efficacy of the drugs, ferrous sulphate and carbonyl iron, in improving the iron stores to meet the increased demand during pregnancy. A comparative study was done in two groups of 36 pregnant women each. One group was supplemented with ferrous sulphate and the other group with carbonyl iron. The biochemical parameters assessing iron status, serum ferritin, serum iron and serum TIBC along with hemoglobin concentration were estimated before and after supplementation in both groups. Though not statistically significant, an increase was seen in the mean levels of serum ferritin in pregnant women who were supplemented with carbonyl iron compared to those who were supplemented with ferrous sulphate. Therefore, carbonyl iron can be preferred over ferrous sulphate in treating iron deficiency anemia in pregnancy, with added advantages of lesser side effects and shorter duration of therapy, which has been established in earlier studies.

(C) 2010 International Formulae Group. All rights reserved.
\end{abstract}

Keywords: Serum iron, serum TIBC, hemoglobin concentration.

\section{INTRODUCTION}

Maternal mortality continues to be a major health problem in the developing world. Nearly 600,000 women die each year as a result of complications in pregnancy and childbirth. Most of these deaths could be prevented with attainable resources and skills (Brabin et al., 2001). A key component of safe motherhood is the eradication of anemia during pregnancy.

Anemia contributes to $24.13 \%$ of maternal deaths in India (Purandare et al., 2007). Furthermore, nutritional anemia, specifically iron deficiency anemia, is associated with preterm birth, low birth weight and for some, a low gestational age of newborn. The WHO has uniform definition of anemia in pregnancy as hemoglobin levels below $11 \mathrm{~g} / \mathrm{dl}$, whereas US Centre for Disease Control and Prevention defines anemia as hemoglobin levels below $11 \mathrm{~g} / \mathrm{dl}$ in first and third trimester and less than $10.5 \mathrm{~g} / \mathrm{dl}$ in second trimester (Killip et al., 2007).

Iron status can be assessed prepartum by using appropriate markers, like blood hemoglobin concentration, serum iron, serum 
total iron binding capacity (TIBC) and predominantly, serum ferritin, which is a biomarker for mobilisable body iron stores.

Ferritin is a high molecular weight glycoprotein that is stable and is not affected by prior ingestion of iron. It reflects the iron stores accurately and quantitatively in the absence of inflammation, particularly in lower range associated with iron deficiency as in pregnancy (Cunningham et al., 2005). Low serum ferritin level is the first abnormal biochemical parameter which indicates iron deficiency (Sharma, 2003).

Iron supplementation is almost universally recommended during pregnancy to correct or prevent iron deficiency because dietary consumption of iron is unlikely to meet the daily dietary recommendation of 30 mg (Sloan et al., 2002). The Government of India, Ministry of Health, recommends 100 $\mathrm{mg}$ of elemental iron and $0.5 \mathrm{mg}$ of folic acid for prophylaxis and $180 \mathrm{mg}$ of elemental iron for the treatment of iron deficiency anemia during pregnancy (Sharma, 2003).

The commonly used iron preparations are ferrous sulphate (available free of cost in most Indian hospitals), ferrous fumarate, ferrous gluconate and more recently, carbonyl iron. Carbonyl iron consists of elemental iron in the form of sub-microscopic crystals of less than $5 \mu \mathrm{m}$ diameter. It has lesser side effects and more elemental iron as compared to ferrous preparations (Gordeuk et al., 1986).

The oral iron supplementation in pregnant women, starting in early pregnancy, appears to be very efficient in preventing anemia in pregnancy.

The objective of this study was to know the therapeutic efficacy of the drugs ferrous sulphate and carbonyl iron in improving the iron stores (done by estimating serum ferritin levels) to meet the increased demand during the third trimester of pregnancy when fetal erythropoesis increases and placenta accumulates iron.

\section{MATERIALS AND METHODS}

This study was conducted for a period of one and half years, starting from February
2008 to August 2009 on pregnant women in their second trimester (between 14-20 weeks of gestation) attending antenatal clinic at M.S. Ramaiah Medical Teaching Hospital and in M. S. Ramaiah Memorial Hospital, Bangalore, India.

An oral informed consent was taken from the pregnant women before the collection of sample. The ethical clearance was obtained from the Ethical Review Board, Medical Education Cell, M.S. Ramaiah Medical College, MSR Nagar, Bangalore, India. The subjects were selected based on the following inclusion and exclusion criteria.

\section{Inclusion criteria}

- Pregnant women of more than 14 weeks of gestation (including primigravida and multigravida);

- Hemoglobin concentration between 9-11 $\mathrm{g} / \mathrm{dl}$;

- Pregnant women on oral iron supplementation with ferrous sulphate and carbonyl iron.

\section{Exclusion criteria}

- Pregnant women of less than 14 weeks of gestation;

- Hemoglobin concentration of less than $9 \mathrm{~g} / \mathrm{dl}$ and more than $11 \mathrm{~g} / \mathrm{dl}$;

- Anemia due to causes other than iron deficiency;

- Pregnancy with other medical illness or any intercurrent infection;

- Pregnant woman not on oral iron supplementation;

- Pregnant woman on oral iron supplementation other than ferrous sulphate and carbonyl iron;

- Miscarriage during course of study.

\section{Study pattern}

Blood samples were collected from pregnant women between 14-20 weeks of gestation and the following laboratory tests were done. 


\section{Hemoglobin concentration $(\mathrm{Hb})$}

The concentration of $\mathrm{Hb}$ was estimated on Sysmex autoanalyser, using heparinised blood sample.

Principle: Non cyanide $\mathrm{Hb}$ analysis method, which estimates volume (gram) of $\mathrm{Hb}$ in one deciliter of whole blood (Gamperling et al., 1998).

\section{Peripheral smear (PS)}

To diagnose the type of anemia, PS was made by placing a drop of blood on one end of a slide, and using a spreader slide to disperse the blood over the slide's length. The aim was to get a region where the cells were spaced far apart to be counted and differentiated. The slide was left to air dry, after which the blood was fixed to the slide by immersing it briefly in methanol. The fixation is essential for good staining and presentation of cellular detail. After fixation, the slide was stained to distinguish the cells from each other.

Wright's stain is a Romanowsky type metachromatic stain made by mixing old or specially treated methylene blue dye with eosin in a methanol diluent. Basic components of the cell, such as hemoglobin or certain inclusions or granules, will unite with the acidic portion of the stain, eosin, and are said to be eosinophilic. These components are stained varying shades of pink or red. Acidic cell components, such as nucleic acids, reactive cytoplasm, etc. take up the basic dye components, methylene azure, and stain blue or purple. $\mathrm{pH}$ must be carefully controlled through the use of a buffer of 6.4-6.7 (Drennan, 1991).

\section{Urine routine}

To detect pre-eclampsia and urinary tract infections. The routine urine analysis includes test for proteins and glucose and microscopic examination of urine. For this, a random urine sample was obtained from the patient and analysis was done. Urine was collected in a clean container and tested as soon as possible. Preservatives were not recommended.

Dipstic method was used for identification of protein or glucose in urine. A
Siemens multiple reagent strip was used. These were firm plastic strips to which were affixed several separate reagent areas. Depending on the product being used, Siemens reagent strips provide tests for glucose, bilirubin, ketone, specific gravity, blood, $\mathrm{pH}$, protein and urobilinogen in urine. The reagent test areas on Siemens Diagnostics Reagent Strips were ready to be used on removal from the bottle and the entire reagent strip was disposable. The strips may be read visually, requiring no additional laboratory equipment for testing.

\section{Stool for ova, cyst and occult blood}

Microscopic examination of stool was done to detect any chronic cause of blood loss like hemorrhoids, worm infestation, etc.

\section{Random blood sugar}

This was evaluated in order to rule out gestational diabetes.

Method: The estimation of blood glucose was carried out on an auto-analyzer, Dade-Behring RXL. The method is an adaptation of Hexokinase and glucose-6-phosphate dehydrogenase (G-6-PDH) method (Kunst et al., 1982). This method is more specific than general reducing methods and gives results lower than those obtained by reducing methods (Henry, 1974).

Principle: Hexokinase (HK) catalyses the phosphorylation of glucose by adenosine5 'triphosphate (ATP) to glucose-6-phosphate which is oxidized to 6-phosphogluconolactone by glucose-6-phosphate dehydrogenase (G-6$\mathrm{PDH}$ ) with simultaneous reduction of nicotinamide adenine dinucleotide phosphate (NADP). One mole of NADP is reduced to one mole of NADPH for each mole of glucose present. The absorbance due to NADPH (and thus glucose concentration) was determined using a bichromatic (340 and $383 \mathrm{~nm}$ ) endpoint technique. Normal Reference Range for Random blood Glucose is $70-120 \mathrm{mg} / \mathrm{dl}$.

\section{Serum ferritin assay}

Method: Enzyme-Immuno-Assay (EIA) gen ferritin kit is a colorimetric immunoenzymatic method for the quantitative determination of the concentration of ferritin in human plasma or serum. 
Principle: EIAgen ferritin kit is based on the simultaneous binding of human ferritin to two monoclonal antibodies: one immobilized on microwell plates, the other conjugated with horseradish peroxide (HPR).

After incubation the bound/free separation is performed by a simple solidphase washing. The enzyme in the bound fraction reacts with the substrate 3,3', 5,5'tetramethylbenzidine (TBM) developing a blue color that turns into yellow after adding the stop solution $\left(\mathrm{H}_{2} \mathrm{SO}_{4}\right)$.The ferritin concentration in the sample is calculated on the basis of a series of calibrators. The intensity is proportional to the ferritin concentration in the sample (Table 1).

\section{Serum iron assay}

Method: The estimation of serum iron was carried out on auto analyzer Dade Behring dimension RXL. The method used was an adaptation of direct iron assays, using the chromophore Ferene (Smith et al., 1984). This method is a direct iron procedure using a surfactant to prevent protein precipitation. A serum blank was used to correct for differences in specimen turbidity. Potential copper interference was minimized by addition of thiourea.

Principle: Under acidic conditions ( $\mathrm{pH} 4.5$ ), iron bound to the protein transferrin is released in the presence of the reducing agent, ascorbic acid. The resulting product, $\mathrm{Fe}^{2+}$ (ferrous) forms a blue complex with 3-(2pyridyl)-5,6-bis-2-(5-furyl sulfonic acid)1,2,4-triazine, disodium salt(Ferene). The absorbance of the complex, measured using a bichromatic $(600,700 \mathrm{~nm})$, endpoint technique, is proportional to the concentration of transferrin-bound iron in the serum.

Normal Reference Range for Serum iron is 35-150 $\mu \mathrm{g} / \mathrm{dl}(6-27 \mu \mathrm{mol} / \mathrm{L})$.

\section{Serum TIBC}

Method: Total iron binding capacity is a measure of the serum transferrin iron binding capacity. Measurements of serum iron and total iron binding capacity are widely used in the diagnosis and the treatment of iron deficiency and chronic inflammatory disorders.
Principle: This is an automated method that involves addition of iron to the sample to saturate the transferrin iron binding sites. The excess unbound iron is photometrically determined (instead of being physically removed by adsorption), in a manner similar to those described by (Yamanishi et al., 1997). Subsequent addition of acids causes the release of bound iron from transferrin, which is then analysed using chromogen Ferene [3(2-pyridyl)-5, 6-bis-2-(5-furyl sulfonic acid)1, 2, 4-triazine, disodium salt]. A surfactant is used to prevent protein precipitation reaction.

The serum or the plasma sample is automatically mixed with ferric iron solution, which saturates all available iron-binding sites of transferrin. Under non-acidic conditions (pH8.6), only unbound, excess saturating iron is available to be reduced to the ferrous iron by ascorbic acid and to form a blue complex with Ferene. Subsequent addition of acid (final $\mathrm{pH}$ of 4.5) releases the iron bound to transferrin; this additional iron is reduced to ferrous iron by ascorbic acid and forms an increased amount of blue complex with Ferene. The increase in absorbance upon shifting from $\mathrm{pH} 8.6$ to 4.5 measured using a bichromatic $(600,700 \mathrm{~nm})$ endpoint technique, is proportional to the concentration of transferrin-bound iron and thus to the iron binding capacity (total) of the serum or plasma sample.

Normal Reference Range for Serum total iron binding capacity is $250-450 \mu \mathrm{g} / \mathrm{dl}$ (44.8-80.6 $\mu \mathrm{mol} / \mathrm{L})$. A comparative study was then conducted between the following two groups:

Group I: Thirty six pregnant women with mild iron deficiency anemia (hemoglobin concentration between 9-11 g/dl), were given oral iron supplementation in the form of ferrous sulphate tablets for a period of twelve weeks.

Group II: Thirty six pregnant women with mild iron deficiency anemia (hemoglobin concentration between 9-11 g/dl) were given oral iron supplementation in the form of carbonyl iron capsules for a period of twelve weeks. 
Re-estimation of the following laboratory tests in the two groups after a period of twelve weeks of supplementation was done: hemoglobin concentration, serum ferritin, serum iron and serum TIBC.

\section{Statistical analysis}

A paired ' $t$ ' test was performed to observe the values of the above parameters before and after supplementation. The students ' $\mathrm{t}$ ' test was used to determine whether there was a statistical difference between group I and group II in the parameters measured. A "p" value of less than 0.05 was considered statistically significant.

Data analysis was done using Statistical Package for Social Science (SPSS, V 10.5) package.

\section{RESULTS}

Table 2 shows the values of the biochemical parameters before and after supplementation in group I. In those pregnant women who received ferrous sulphate for a period of 12 weeks, the hemoglobin concentration significantly $(' p '=0.002)$ increased. Also there was an increase in mean levels of serum ferritin and serum iron. There was a strongly significant $(' p '=0.000)$ increase in serum TIBC levels after supplementation in this group

Table 3 gives the data of group II. There was a significant ('p'=0.000) rise in hemoglobin concentration and an increase in mean value of serum ferritin after supplementation. There was a fall in serum iron levels after supplementation and serum TIBC remained almost the same before and after supplementation.

Table 4 compares the study parameters in the two groups after supplementation. Mean increase in $\mathrm{Hb} \%$ was seen more in carbonyl iron group as against ferrous sulphate group. Serum ferritin which is a marker of iron reserves in the body also showed an improvement in carbonyl iron group than in ferrous sulphate group. However these improvements were not statistically significant. Serum iron has shown a mean increase in ferrous sulphate group. But in the carbonyl iron group, there was fall in mean value by $6.89 \mu \mathrm{g} / \mathrm{dl}$. Serum TIBC level showed significant $(\mathrm{p}<0.001)$ difference in mean value between the two groups. In group I, the TIBC level increased by a mean of $203.11 \mu \mathrm{g} / \mathrm{dl}$ but in group II, the increase was only $0.54 \mu \mathrm{g} / \mathrm{dl}$.

\section{DISCUSSION}

The physiologic solution for covering the high iron requirements in pregnancy is to use iron from stores. The problem however is that very few women, if any, have iron stores, of this magnitude (Commission of European Committees, 1993). In order to considerably obtain an adequate iron store, the women should make unrealistic changes in their diet. The duration of gestation is too short and the benefit of modifying the diet is too limited to have a meaningful impact on evolution of iron deficiency anemia (IDA) during pregnancy. Even under favourable conditions, at most $30 \%$ of dietary iron can be absorbed, corresponding to $3 \mathrm{mg}$ iron per day, which is considerably less than daily iron requirement during pregnancy. As we realize that dietary iron cannot fulfill iron requirements during pregnancy, it is necessary to advocate oral iron supplements to women with iron stores less than $500 \mathrm{mg}$ or serum ferritin less than 70 $\mu \mathrm{g} / \mathrm{L}$ (Milman, 2008). Therefore daily iron supplements are recommended in the latter half of the pregnancy.

Ferrous sulphate is one of the oldest and earliest forms of oral iron supplementation used to treat IDA. It has increased solubility and availability at the $\mathrm{pH}$ of duodenum and jejunum. When given on an empty stomach, side effects like epigastric pain, nausea, vomiting and diarrhea may occur, which are relieved to a certain extent when administered after meals (Umbriet, 2005). Carbonyl iron is small particle preparation of highly purified metallic iron. "Carbonyl" describes the process of manufacture of the iron particles, not their composition. Heating gaseous iron pentacarbonyl $\left[\mathrm{Fe}(\mathrm{CO})_{5}\right]$, deposits metallic iron as sub-microscopic crystals that form 
Table 1: Normal serum ferritin values are as follows.

\begin{tabular}{lcc}
\hline Age group & Mean $\mathbf{~ n g / m l ~ ) ~}$ & Range ( ng/ml ) \\
\hline Fertile women (15-49 years) & 53 & $6-180$ \\
Post menopausal women & 105 & $8-350$ \\
Adult men & 175 & $20-400$ \\
\hline
\end{tabular}

Table 2: Comparison of study parameters prior and after supplementation in group I (supplemented with ferrous sulphate).

\begin{tabular}{lccc}
\hline Parameters & $\begin{array}{c}\text { Sample I } \\
(\mathbf{1 4 - 2 0} \text { weeks) } \\
\text { Mean } \pm \text { S.D }\end{array}$ & $\begin{array}{c}\text { Sample II } \\
(\mathbf{2 6 - 3 2 w e e k s )} \\
\text { Mean } \pm \text { S.D }\end{array}$ & 'p' value \\
\hline $\mathrm{Hb} \%$ & $10.24 \pm 0.86$ & $11.08 \pm 1.46$ & \\
Sr.ferritin $(\mu \mathrm{g} / \mathrm{L})$ & $12.28 \pm 22.81$ & $13.75 \pm 16.55$ & 0.002 \\
Sr.iron $(\mu \mathrm{g} / \mathrm{dl})$ & $58.19 \pm 39.07$ & $64.78 \pm 34.96$ & 0.591 \\
Sr.TIBC $(\mu \mathrm{g} / \mathrm{dl})$ & $234.22 \pm 134.49$ & $437.33 \pm 94.95$ & 0.441 \\
\hline
\end{tabular}

Sr.: serum, Hb: hemoglobin, TIBC: total iron binding capacity.

Table 3: Comparison of study parameters prior and after supplementation in group II (supplemented with carbonyl iron).

\begin{tabular}{lccc}
\hline Parameters & $\begin{array}{c}\text { Sample I } \\
(\mathbf{1 4 - 2 0} \text { weeks })\end{array}$ & $\begin{array}{c}\text { Sample II } \\
(\mathbf{2 6 - 3 2} \text { weeks })\end{array}$ & 'p' value \\
& Mean \pm S.D & Mean \pm S.D & \\
\hline $\mathrm{Hb} \%$ & $10.58 \pm 0.67$ & $11.89 \pm 1.25$ & 0.000 \\
$\mathrm{Sr}$. ferritin $(\mu \mathrm{g} / \mathrm{L})$ & $11.95 \pm 15.55$ & $16.54 \pm 15.61$ & 0.146 \\
$\mathrm{Sr}$. iron $(\mu \mathrm{g} / \mathrm{dl})$ & $72.33 \pm 59.20$ & $65.44 \pm 40.00$ & 0.558 \\
$\mathrm{Sr} . \mathrm{TIBC}(\mu \mathrm{g} / \mathrm{dl})$ & $439.58 \pm 197.26$ & $440.12 \pm 128.31$ & 0.991 \\
\hline $\mathrm{Sr} \cdot$ serum $\mathrm{Hb} \cdot$ hemoglobin, $\mathrm{TIBC} \cdot$ total iron binding capacity & &
\end{tabular}

Table 4: Change (mean difference) in Hb, serum ferritin, serum iron and serum.TIBC after oral iron supplementation in the study groups.

\begin{tabular}{lccc}
\hline Parameter & $\begin{array}{c}\text { Group I } \\
\text { (Ferrous sulphate) } \\
\text { Mean } \pm \text { S.D }\end{array}$ & $\begin{array}{c}\text { Group I } \\
\text { (carbonyl iron) } \\
\text { Mean } \pm \text { S.D }\end{array}$ & 'p' value \\
\hline $\mathrm{Hb} \%$ & $0.84 \pm 1.47$ & $1.31 \pm 1.41$ & 0.168 \\
Sr.ferritin $(\mu \mathrm{g} / \mathrm{L})$ & $1.46 \pm 16.19$ & $4.59 \pm 18.52$ & 0.448 \\
Sr.iron $(\mu \mathrm{g} / \mathrm{dl})$ & $6.58 \pm 50.67$ & $6.89 \pm 69.89^{*}$ & 0.352 \\
Sr.TIBC $(\mu \mathrm{g} / \mathrm{dl})$ & $203.11 \pm 157.38$ & $0.54 \pm 268.89$ & $<0.001$ \\
\hline
\end{tabular}

Sr.: serum, Hb: hemoglobin, TIBC: total iron binding capacity;

* fall in serum iron after supplementation in carbonyl iron. 
spheres of less than $5 \mu \mathrm{m}$ in diameter. Solubilisation of carbonyl iron by gastric acid is a pre-requisite for absorption. The slow rate of solubilisation results in a more prolonged absorption which is responsible for low toxicity of carbonyl iron (Brittenham et al., 2001). Robotham and Lietman (1980) in their study involving adult human volunteers have demonstrated that the $10.000 \mathrm{mg}$ dose of carbonyl iron (which is over half the lethal dose as ferrous sulphate) when given to four volunteers developed no evidence of toxicity. Studies by Gorduek et al. (1986) have shown that patient with mild IDA, can correct anemia and rebuild iron stores with short course of carbonyl iron. Gorduek et al. (1987) in a similar study had found that treatment with low dose carbonyl iron may be effective to treat IDA with in the present length of time necessary for treatment with ferrous salt and yet have few or no side effects or risk of poisoning in children.

The above mentioned studies were done in general population, anemic patients in general and in female blood donors. The present study is therefore targeted to compare the therapeutic efficacy of ferrous sulphate and carbonyl iron in pregnant women which was not done earlier.

The observations made in our study suggest that carbonyl iron is effective in the treatment of iron deficiency anemia in pregnant women. It can be considered as a useful, relatively novel, and alternative formulation for treatment of IDA during pregnancy, which is indicated by mean increase in $\mathrm{Hb} \%$ and serum ferritin, when compared to the conventional preparation ferrous sulphate. The fall in serum iron after supplementation in carbonyl iron group can be explained as follows. The normal serum iron level is $35-150 \mu \mathrm{g} / \mathrm{dl}$. The mean values obtained in our study are well within the normal range and any fluctuation within this range is a common phenomenon in pregnancy (Chang, 1973) as there is a constant absorption and utilization of iron taking place, upon which the hematological adaptations during pregnancy explain the variations in serum iron levels. Moreover a fall within the normal range should not be a matter of concern.

Serum TIBC level shows significant difference in mean value between the two groups. A common finding in both groups is an elevated serum TIBC in late pregnancy. We know that serum TIBC levels are high in IDA and following iron therapy the levels should decrease (transferrin exists in two phases: circulating and sequestrated phase. In IDA, the equilibrium is shifted to circulating phase producing high TIBC and low serum iron; and following iron supplementation there is lowering of this elevated transferrin levels (Mandel, 1958). The finding in our study is contradictory to this established fact and can be explained as follows:

In normal pregnancy, there is increased synthesis of plasma proteins, specifically, the globulin fraction. Transferrin is a $\beta_{1}$ globulin which transports iron in the blood. This may be a consequence of increased estrogens during pregnancy, stimulating the rise in serum binding capacities, not only of iron, but also other hormones like thyroxine and corticosteroids (Dowling et al., 1960). It has also been suggested that raised serum transferrin levels may result in increased iron absorption (Fletcher et al., 1968). A study by Laurell (1947) proposed that the rise in iron binding capacity of plasma serves the useful purpose of enhancing mobilization of iron from maternal stores, thus enabling easier transport to the fetus. A recent study on experimental animals has demonstrated an increase in mRNA transferrin in late gestation in maternal and fetal liver. Additionally, the placenta expresses a gene homologous to liver transferrin and it is also upregulated in late gestation (Kasik et al., 1993). Finally, ferrous sulphate is one of the many interfering substances in direct estimation of serum TIBC, using an autoanalyser. Ferrous sulphate level of $250 \mu \mathrm{g} / \mathrm{dl}$ in the blood increases results obtained for serum TIBC by $17 \%$. This explanation holds valid for group I only. 
The point which remains to be explained is raised TIBC before supplementation in the group supplemented with carbonyl iron. The subjects of this group are from upper socioeconomic status, so their intake of iron rich diet from the first trimester of pregnancy is more when compared to the other group. Since raised TIBC levels denote increased iron absorption, this could be one of the reasons for a rise in TIBC levels in the pre-supplementation phase.

Thus, our study, based on mean values infers that carbonyl iron can be preferred over ferrous sulphate for prophylaxis as well as for the treatment of mild iron deficiency anemia in pregnancy.

We recommend a similar study to be done in larger group of pregnant women to reinforce our findings.

\section{REFERENCES}

Brabin BJ, Mohammad H, Pelletier D. 2001. An analysis of anemia and pregnancy related maternal mortality. Journal of Nutrition, 131: 604S-615S.

Brittenham GM, Klien HG, Kushner JP, Ajioka RS. 2001. Preserving the National blood supply. American Society of Hematology, 2001(1): 422-432.

Chang LL, Chua K, Yong YC, Sivasamboo R. 1973. Plasma transferrin in Singapore women during preganacy. Sing Med J., 14(4): 477-479.

Commission of European committees. 1993. Nutrient and energy intakes for the European community. Report of Scientific Committee for Food. Directorate General Industry $31^{\text {st }}$ series, 180-1.

Cunningham, Gary F, Leveno KJ. 2005. William's Obstetrics. Hematological Disorders (22nd edn). McGraw Hill; 1144-1146.

Dowling JT, Freinkel N, Ingbar SH. 1960. The effect of estrogen upon the peripheral metabolism of thyroxine. J. Clin. Invest., 28: 487.

Drennan. 1991. Hematology Laboratory: Proper Preparation of a Peripheral Blood
Smear. Slide Staining with Wright's Stain.

Fletcher J, Huehns ER. 1968. Function of transferrin. Nature, 218: 1211.

Gamperling N, Mast JB, Hagbloom R, Houwen B. 1998. Performance evaluation of the Sysmex KX-21 automated hematology analyser. Sysmex Journal International, 8: 96-101.

Gordeuk VR, Brittenham GM, Hughes M, Keating LJ, Opplt JJ. 1986. Carbonyl iron therapy for iron deficiency anemia. The American Society of Hematology, 67(3): 745-752.

Gordeuk VR, Brittenham GM, Hughes M, Keating LJ, Opplt JJ. 1987. High-dose carbonyl iron for iron deficiency anemia:A randomized double-blind trial. The American Journal of Nutrition, 46: 1029-34.

Henry RJ. 1974. Clinical Chemistry Principles and Techniques. Harper and Row: New York; 1283.

Kasik J, Rice E. 1993. Transferrin gene expression in maternal liver, fetal liver and placenta during pregnancy in the mouse. Placenta, 14(4): 365-371.

Killip S, Bennett JM, Chambers MD. 2007. Iron deficiency anemia. American Family Physicians Journal, 75(5): 1-14.

Kunst A, Draeger, B Ziegenhorn J. 1982. UVmethods with hexokinase and glucose-6phosphate dehydrogenase. Methods of Enzymatic Analysis, 4: 163-172.

Laurell CB. 1947. Studies of transportation and metabolism of iron in the body, with special reference to iron binding component in human plasma. Acta Physio. Scand., 14(46): 72.

Mandel EE. 1958. Serum iron and iron binding capacity in clinical diseases. Clinical Chemistry, 5(1): 1-12.

Milman N. 2008. Prepartum anemia: prevention and treatment. Ann. Hematol., 87: 949-959.

Purandare N, Singh A, Chandock, Upadhya S, Sanjanwala SM, Saraogi RM. 2007. Maternal mortality at a referral center: a 
five year study. Journal of obstetrics and gynaecology, 57(3): 248-250.

Robotham JL, Lietman PS. 1980. Acute iron poisoning: A review. Am. J. Dis. Child., 134: 875 .

Sharma JB. 2003. Progress in obstetrics and gynecology by John Studd: Nutritional anemia during pregnancy in nonindustrialized countries. Churchill Livingstone, 15: 103-122.

Sloan NL, Elizabeth J, Beverly W. 2002. Effects of iron supplementation on maternal hematologic status in pregnancy. Am. J. Public Health, 92(2): 288-293.
Smith FE, Herbert J, Gaudin J, Hennessy J, Reid GR. 1984. Serum iron determination using ferene triazene. Clin Biochem., 17: 306-310.

Umbriet R. 2005. Iron deficiency: A concise review. American Journal of Hematology, 78: $225-231$.

Yamanishi H, Kimura S, Iyama S, Yamaguchi Y, Yanagihara T. 1997. Fully automated measurement of total iron binding capacity in serum. Clin. Chem., 43(12): 2413-2417. 